\title{
INVESTIGATION OF ELECTRICAL PROPERTIES HOMOGENEITY OF Li-Ti-Zn FERRITE CERAMICS
}

\author{
Nikolaev E.V. ${ }^{1}$, Astafyev A.L. ${ }^{1}$, Nikolaeva S.A. ${ }^{1}$, Lysenko E.N. ${ }^{1}$, Zeinidenov A.K. ${ }^{2}$ \\ 1National Research Tomsk Polytechnic University, Tomsk, Russia, nikolaev0712@gmail.com \\ 2E.A. Buketov Karaganda State University, Karaganda, Kazakhstan
}

\begin{abstract}
In this article the distribution of electrical conductivity homogeneity of lithium ferrite ceramics was studied. Investigations of the conductivity were performed on samples of lithium substituted ferrite with addition of zirconium dioxide $(0 \% ; 0.2 \% ; 0.3 \% ; 0.5$ weight \%). Experimental samples were sintered at $1010{ }^{\circ} \mathrm{C}$ for 2 hours by using the standard ceramic technology. Temperature dependences of electrical conductivity were obtained by the two-probe method (spreading resistance analysis). According to spreading resistance analysis, it was found that the distribution of electrical conductivity in the surface layers varies depending on the chemical composition and this distribution has inhomogeneous character. Also, the activation energy and measurement error were calculated.
\end{abstract}

Keywords: lithium ferrites, ceramics, electrical conductivity, zirconium dioxide.

\section{Introduction}

Ferrite ceramics have a wide range of applications and are used in the most modern electronic computing and radio devices $[1,2]$. One of those materials are lithium ferrites, which are widely used in technique that is used both at radio frequencies and at ultrahigh frequencies (microwave range), as well as like cathodes of lithium batteries $[3,4]$. The high demand for these materials is due to the low cost of this class of ferrites and excellent ferromagnetic properties. For example, high values of the Curie temperature and saturation magnetization [5], beside low values of dielectric losses [6]. These properties are important for creating ferrite devices with magnetic memory [7].

Spinel of lithium ferrite contains reducible iron ions and lithium ions therefore it is expected that this material has both electronic and ionic conductivity [8]. Experimental data show the electrical conductivity of ferrites increases significantly when ions with different valences are located in equivalent crystallographic positions. The electrical conductivity of ferrites is explained by the Verwey mechanism [9], which means that electrons hop from ion to ion. In this case, the valence of the ions changes in accordance with the expression:

$$
M e_{1}^{g+}+M e_{2}^{r+} \leftrightarrow M e_{1}^{(g-1)}+M e_{2}^{(r+1)} .
$$

In case when ferrite has the same ions in equivalent crystallographic lattice sites, which has differ by one, then both ions exchange their valences. The corresponding valence states migrate along the crystal, and if it has a sufficiently high concentration of ions with different valences so it leads to high conductivity.

From the Verwey mechanism of electrical conductivity discussed above, it follows that the conductivity of ferrites is more dependent on the content of multivalent ions in them. Such ions in ferrites are often iron ions, as well as ions of zinc, manganese, titanium, and some others [10].

The ceramic method is a classic method of manufacturing lithium ferrospinels, which includes a synthesis stage with the formation of a single-phase product and a further sintering stage at high temperatures [11-13]. However, during high-temperature annealing, the capabilities of this method are limited by the low thermal stability of some reagents [14] (evaporation of lithium and zinc oxide)of the initial mixture and their incomplete ferritization. For this reason, it is observed 
probability of increasing of adverse phase inclusions and decreasing of the chemical and product structural homogeneity. These facts lead to a deterioration in its structural, electrical and magnetic properties, which increases the yield of defective products $[15,16]$.

Conventional methods for solving these problems are using of additional technological methods, including operations of multiple grinding, briquetting and subsequent firing of reaction mixtures. At the same time, such approaches are extremely laborious, energy consuming, and difficult to implement due to the multiple increase in intermediate operations. In addition, the appearance probability of impurities (contaminants) in the reaction mixture is increased.

Effective methods to reduce sintering temperature include such methods as adding oxides with a low melting point, ball mill grinding [17-20], sol-gel [21], and other technologies [22-24]. It was shown in $[25,26]$ that heating reagents with intense electron beams is an effective method of intensifying solid-state reactions [27], leading to a decrease in the synthesis temperature and an increase in the homogeneity of ferrites [28].

Despite the availability of ferrite production around the world, there are still problems associated with the need to improve the quality of products. In the same time, the development and improvement of electronic technology is accompanied by an ever-increasing tightening of requirements for magnetic materials. Today, there is an urgent necessity for highly specialized magnetic materials with a certain combination of electro-physical and magnetic properties. Alloying lithium and lithium substituted ferrites with different additives allow achieving the necessary characteristics or improving existing electrical, magnetic and mechanic characteristics. It allows get almost any properties inherent in more expensive materials.

Several types of added additives can be distinguished: ones of those form a liquid phase during sintering, thereby affecting the ferrite microstructure, others are located at the grain boundaries as the second phase, which has a very high resistivity. In addition, some additives can be integrated into the ferrite lattice and replace ions at tetrahedral or octahedral levels.

Recently, zirconium dioxide has become an effective additive allowing one to influence the properties and structural state of a wide class of materials [29-31]. Previous scientific results show the additive affects the structure of ferrites, which makes it possible to control other structurally sensitive properties, such as electrical conductivity [32], magnetic permeability [33], thermal conductivity [34], and the shape of the hysteresis loop.

Therefore, there is every reason to suppose that the introduction of zirconia additives can be used in the manufacture of lithium ferrites. This can effect on the formation of structural and electromagnetic characteristics and will allow obtain improved properties compared with prototypes. Thus, the homogeneity of the distribution of electrical conductivity in the surface layers of multi-component lithium ferrite (with the chemical composition $\mathrm{Li}_{0.65} \mathrm{Fe}_{1.6} \mathrm{Ti}_{0.5} \mathrm{Zn}_{0.2} \mathrm{Mn}_{0.05} \mathrm{O}_{4}$ ) was studied. The effect of the introduction of zirconia additives on the electrical properties of this ferrite is considered.

\section{Experimental part}

The measurements were carried out on samples of Li-Ti- $\mathrm{Zn}$ ferrite with a low contain of $\mathrm{ZrO}_{2}$ additive. The initial reagents were chemically pure powders of zinc oxide $(\mathrm{ZnO})$, manganese oxide $(\mathrm{MnO})$, zirconium dioxide $\left(\mathrm{ZrO}_{2}\right)$, titanium dioxide $\left(\mathrm{TiO}_{2}\right)$ and iron oxide $\left(\mathrm{Fe}_{2} \mathrm{O}_{3}\right)$, as well as lithium carbonate $\left(\mathrm{Li}_{2} \mathrm{CO}_{3}\right)[32,33]$. All initial reagents were pre-dried in a laboratory furnace at a temperature of $200{ }^{\circ} \mathrm{C}$ for 240 minutes.

In accordance with the chemical equation $\left(\mathrm{Li}_{0.65} \mathrm{Fe}_{1.6} \mathrm{Ti}_{0.5} \mathrm{Zn}_{0.2} \mathrm{Mn}_{0.05} \mathrm{O}_{4}\right)$, the initial reagents were weighed on Shimadzu AUW-D digital analytical balances. Then powders were mixed in an agate mortar with tenfold rubbing through a metal sieve with a mesh size of $100 \mu \mathrm{m}$. It was done to achieve the most uniform distribution of the initial reagents. The mixture of initial powders was divided into four equal parts, after that the zirconia $\left(\mathrm{ZrO}_{2}\right)$ was added in different weight ratios to each part. The weight content of $\mathrm{ZrO}_{2}$ additive was $0 ; 0.2 ; 0.3 ; 0.5$ wt. \%. 
Each part of the mixture was mechanically activated in EMAX (Retsch) high-speed ball mill to increase the homogeneity of the distribution of zirconium dioxide in the mixture and its reactivity [34-35]. Mechanical activation was carried out in steel grinding vials and balls with a diameter of 2 $\mathrm{mm}$. The weights of the mixture and balls were in the ratio 1:10. The mechanical activation was performed at $2000 \mathrm{rpm}$ for 30 minutes.

Mechanically activated powders were pressed by single-sided cold pressing in a hydraulic hand press PGr-10. The pressing pressure was $200 \mathrm{MPa}$. The pressing time was 3 minutes. After pressing, the samples had a cylindrical shape with a diameter of $15 \mathrm{~mm}$.

The studied samples were sintered at $1010^{\circ} \mathrm{C}$ for 120 minutes in a laboratory resistance furnace in an air atmosphere. The X-ray diffraction analysis was carried out by using ARL X'TRA (Switzerland) diffractometer with a semiconductor $\mathrm{Si}$ (Li) Peltier detector and $\mathrm{Cu} \mathrm{K}_{\alpha}$ radiation. XRD patterns were measured in the range $2 \theta=(10-70)^{\circ}$ with scanning rate of $0.02^{\circ} \cdot \mathrm{sec}^{-1}$ and were processed by the full profile analysis using the Powder Cell 2.5 software, where the pseudo-Voigt profile function was used. Phases were identified by the PDF-4+ powder database of the International Center for Diffraction Data (ICDD). The electrical characteristics of the samples were measured by the two-probe method [36].

It is possible to record the current change during the heating of sample with using this method. The studying sample is located on a substrate, which is gradually heated to a temperature of $540 \mathrm{~K}$ with using a spiral heater. Two probes are fixed on the surface of the sample, one of which is supplied with a voltage of $5 \mathrm{~V}$, and the measured current is detected from the other probe with a voltmeter. This method is characterized by a high locality of measurements, since the spreading resistance is determined mainly by the contact area. The volume of the region where the resistivity is determined is approximately $10^{-10} \mathrm{~cm}^{3}$. According to the data, which obtained from measurements by the two-probe method, it is possible to calculate the volume resistivity by the equation:

$$
\rho=\frac{U \cdot r_{o} \cdot \pi}{I},
$$

where $U$ is the applied voltage, $I$ is the current, $r_{0}$ is the diameter of the contact.

The diameter of the contact is approximately $10 \mu \mathrm{m}$ and corresponds to the spatial resolution of the method. For Li-Ti-Zn ferrite samples, temperature dependences of the current on temperature were obtained. Each sample was heated from room temperature to $540^{\circ} \mathrm{K}$. To determine the accuracy of the study, the surface current of each sample was measured at four points. According to the temperature dependences of the current, experimental curves were calculated in the coordinates $\operatorname{Ln}(\mathrm{I})=f(1 /(\mathrm{k} \cdot \mathrm{T}))$ to determine the activation energy. The activation energy is defined as the tangent of the angle of inclination to the approximation curve [37].

\section{Results and discussions}

Figure 1 shows X-ray diffraction patterns of Li-Zn-Ti ferrite with a $\%$ content of $\mathrm{ZrO}_{2}$ and the initial powder of $\mathrm{ZrO}_{2}$. Diffraction patterns show all the high-intensity reflections which belongs to zirconium dioxide, coincide with the Li-Zn-Ti ferrite reflections. Only one reflection located at $2 \theta \approx 51^{\circ}$ does not coincide. By the presence of reflections at these angles, it is possible to detect zirconium dioxide in the composition of ferrite, however, the small weight content of $\mathrm{ZrO}_{2}$ in the mixture, as well as the presence of overlapping reflections, does not allow to detecting its content in the studied samples.

Figure 2 shows the diffraction patterns of the initial powder components $\mathrm{Fe}_{2} \mathrm{O}_{3}$ (JCPDS No. 40-142), $\mathrm{Li}_{2} \mathrm{CO}_{3}$ (JCPDS No. 66-941) and $\mathrm{TiO}_{2}$ (JCPDS No. 82-656) phases. 


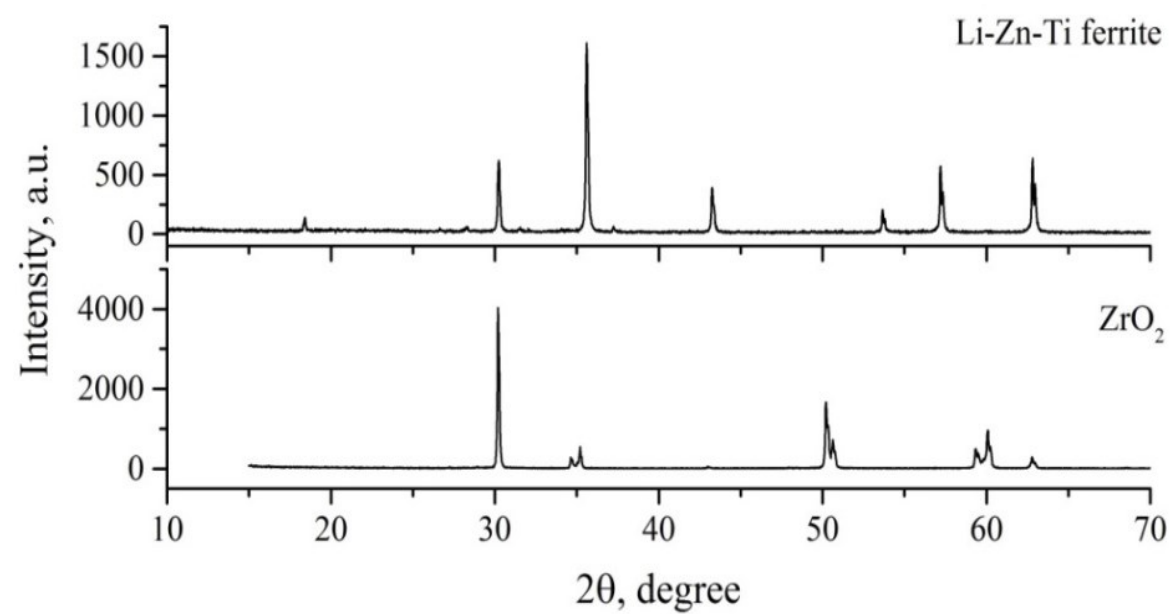

Fig.1. X-ray diffraction patterns of $\mathrm{Li}-\mathrm{Zn}$-Ti ferrite and $\mathrm{ZrO}_{2}$ powder

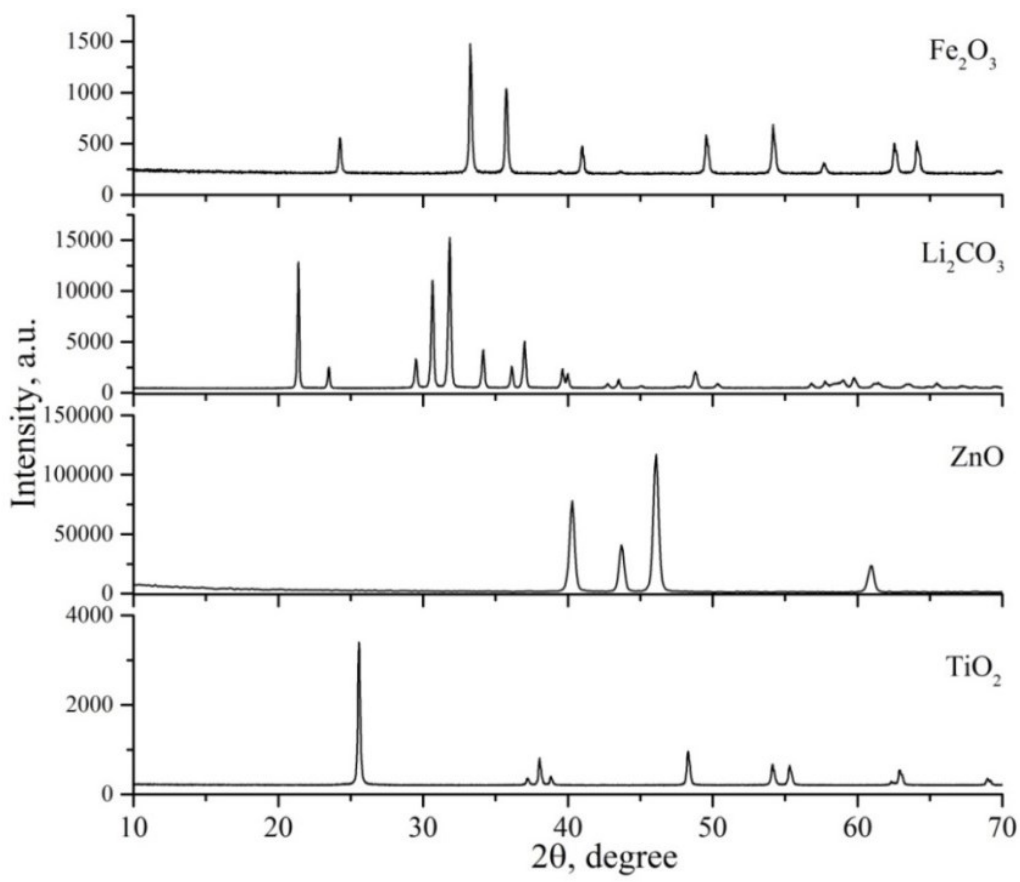

Fig.2. X-ray diffraction pattern of initial powders

Analysis X-ray diffraction patterns shows absences of reflections which can be belong to initial powder and all observed reflection belongs to spinel phase. It shows that the selected technological modes of sintering, pressing, as well as the time and energy of mechanical activation allow us to obtain the spinel phase, which corresponds to final composition of $\mathrm{Li}-\mathrm{Zn}-\mathrm{Ti}$ ferrite without impurities. For all Li-Ti-Zn ferrite samples, current measurements were carried out during the heating of the sample. Values of the current were taken on the surface of the sample at four randomly selected points.

Figure 3 shows the temperature dependences of the bulk conductivity current for a sample without zirconia, which measured at four points on the surface. The temperature curves of the bulk conductivity current are characterized by a linear dependence in logarithmic coordinates $\operatorname{Ln}(I)=f(1 / k T)$. With increasing temperature, an increase in electrical conductivity is observed, which is characteristic of lithium ferrites. 
Figures 4, 5 and 6 show curves for samples with additive of zirconium dioxide $(0.2,0.3$ and $0.5 \mathrm{wt} \%$ ). In these graphs, the curves are located as close as possible to each other, which indicate a small experimental error and may indicate a uniform distribution of electrical conductivity over the surface of the sample.
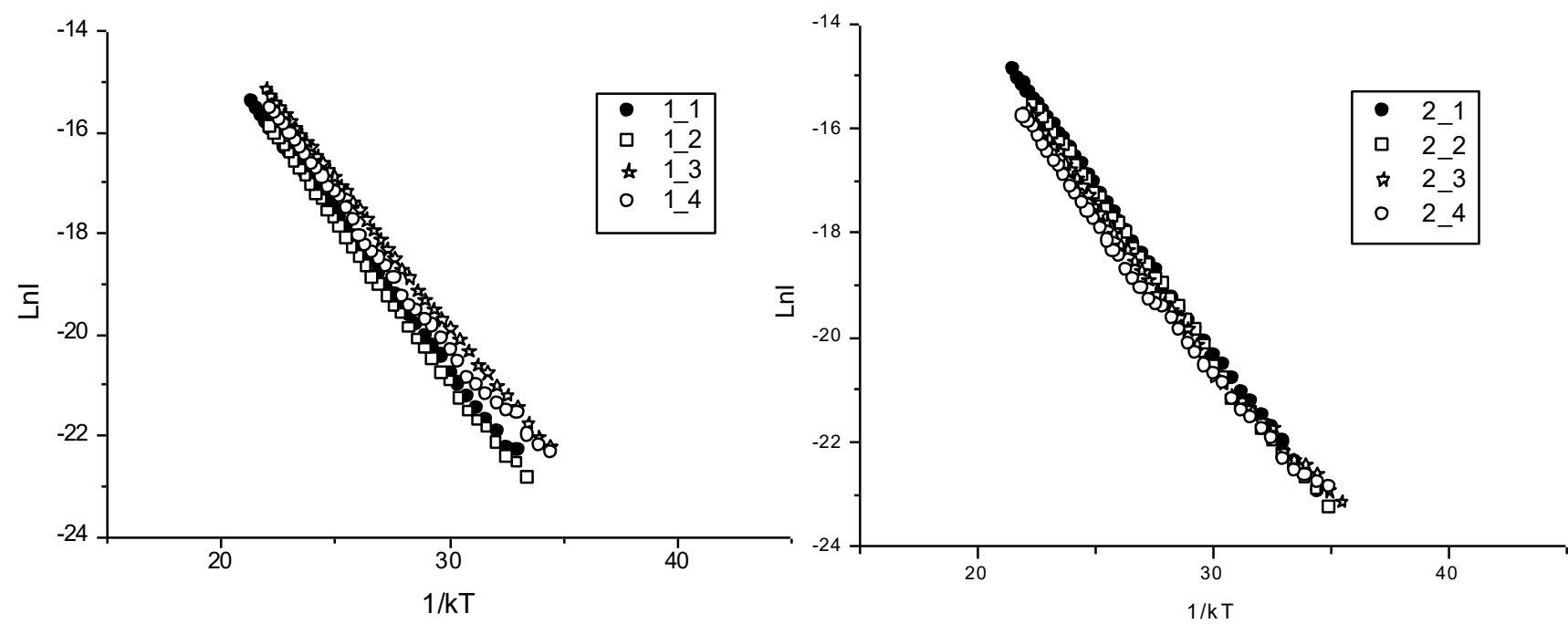

Fig.3. The temperature dependence of conductivity current for samples without $\mathrm{ZrO}_{2}$

Fig.4. The temperature dependence of conductivity current for Li-Ti-Zn ferrite with $0.2 \mathrm{wt} \% \mathrm{ZrO}_{2}$

The linear form of dependence without kinks in Figures 3-6 indicates that in the temperature range $300-540{ }^{\circ} \mathrm{K}$ there is only one conduction mechanism with a certain activation energy. This type of temperature dependence is due to a change in electron mobility in Li-Ti-Zn ferrite, during the heating of the sample. In this case, the Vervey mechanism of conductivity is best suited to describe the mechanism of electrical conductivity.

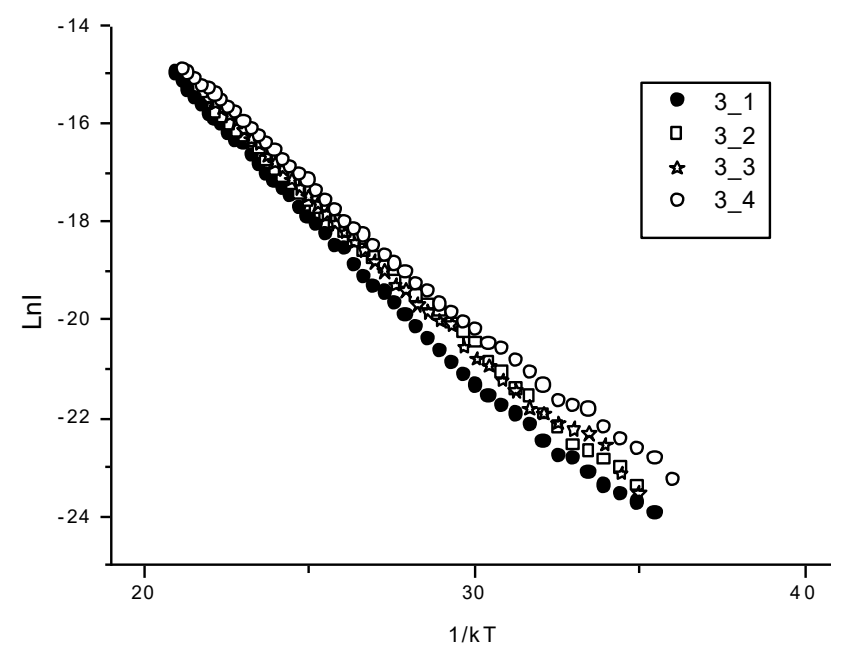

Fig.5.The temperature dependence of conductivity current for $\mathrm{Li}-\mathrm{Ti}-\mathrm{Zn}$ ferrite with $0.3 \mathrm{wt} \% \mathrm{ZrO}_{2}$

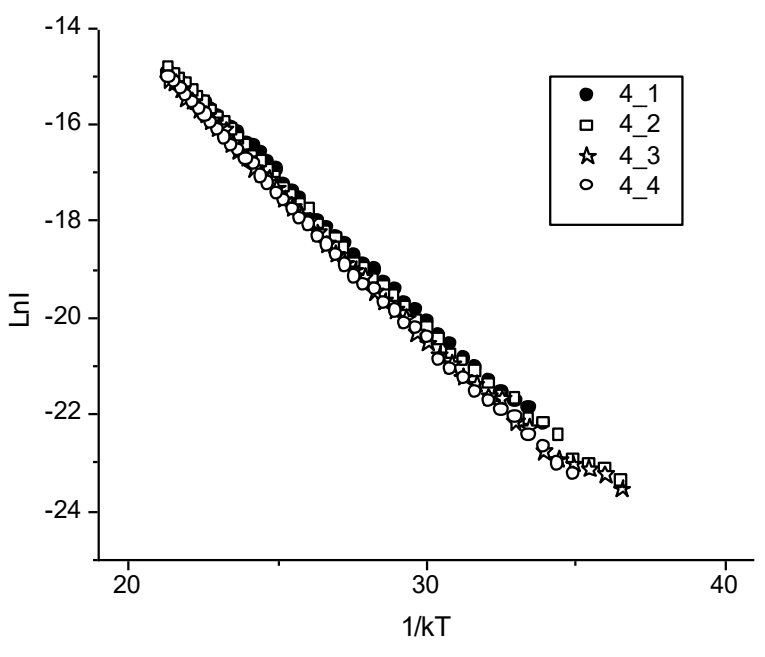

Fig.6. The temperature dependence of conductivity current for Li-Ti-Zn ferrite with $0.5 \mathrm{wt} \% \mathrm{ZrO}_{2}$

This mechanism explains the electrical conductivity of ferrites by the process of electron hopping from ion to ion, so the electrical conductivity will depend on the content of multivalent ions in the ferrite. For Li-Ti-Zn ferrite samples, the electrical conductivity will be determined by electron hopping between the multivalent iron ions $\mathrm{Fe}^{2+}$ and $\mathrm{Fe}^{3+}$. 
In Figures 3-6, the electrical conductivity of ferrite samples increases during the heating process. The similar character of the dependences $\operatorname{Ln}(\mathrm{I})=f(1 / k T)$ for samples with and without zirconium dioxide indicates that additive of zirconium dioxide does not significantly effect on the mechanism of electric conductivity in lithium ferrites. A slight change of the electrical characteristics may be due to the effect of zirconium dioxide on the microstructural properties of LiTi-Zn ferrite. As it is known, microstructural properties can effect on the electrical characteristics. So, for example, a decrease of grain size and an increase of porosity can affect on the electrical resistance of ferrites.

The experimental temperature curves were used to calculate the activation energy $\left(\mathrm{E}_{\mathrm{a}}\right)$. The activation energy can be calculated if obtained experimental points fit in a straight line. In this work, the activation energy was calculated for all samples; the average value of the activation energy based on four measurements is presented in Table 1 (column 2). Also, for each measurement, the volume resistivity was calculated according to equation 1 , the average value of the resistivity can be seen in table 1 (column 4). From the data of Table 1 it can be seen that the samples have a high volume resistivity. The activation energy and resistivity data, which obtained from the surface of samples with different $\mathrm{ZrO}_{2}$ additive contents, have an insignificant difference, which indicates that small additions of zirconium dioxide up to $0.5 \%$ do not significantly affect the electric conductivity in Li-Ti-Zn ferrite.

Table 1. Electrophysical parameters of Li-Ti-Zn ferrite

\begin{tabular}{|c|c|c|}
\hline Additive of $\mathrm{ZrO}_{2}, \%$ & $E_{a}, \mathrm{eV}$ & $\rho, \mathrm{GO} \mathrm{m} \cdot \mathrm{cm}$ \\
\hline 0 & $0.597 \pm 0.03059$ & $1.45 \pm 0.175$ \\
\hline 0.2 & $0.594 \pm 0.02803$ & $1.34 \pm 0.109$ \\
\hline 0.3 & $0.604 \pm 0.03086$ & $1.58 \pm 0.206$ \\
\hline 0.5 & $0.593 \pm 0.02775$ & $1.27 \pm 0.115$ \\
\hline
\end{tabular}

According to Table 1, we can conclude that the electrical resistivity is evenly distributed over the surface of the sample; the deviation from the average value of the activation energy for each sample based on four measurements is not more than $7 \%$. So the largest variation of the measurement is the sample without the addition of zirconium dioxide. For this sample, the actual error of the activation energy value exists in the probability interval with a standard deviation of \pm $0.03059 \mathrm{eV}$ at an arbitrary temperature of the sample in the temperature range $300-540{ }^{\circ} \mathrm{K}$.

\section{Conclusion}

In the presented work, samples of Li-Ti-Zn ferrite with the addition of zirconium dioxide were made by the standard ceramic technology (Conventional method). X-ray phase analysis showed the presence of a spinel phase which corresponds to phase of final Li-Ti-Zn ferrite. This fact indicates a complete ferritization process.

In this article, small additives of zirconium dioxide up to $0.5 \mathrm{wt} \%$ were considered, it was found that such a low content of the additive does not has significantly affect on the electrically transfer process in Li-Ti-Zn ferrite. The samples under study possess semiconductor properties; an increase in the conductivity is observed with an increase in the temperature of the samples.

For the studied lithium ferrite, the conduction mechanism in the temperature range $300-540{ }^{\circ} \mathrm{K}$ is determined by electron hopping between the multivalent ions $\mathrm{Fe}^{2+}$ and $\mathrm{Fe}^{3+}$. It was found that the deviation from the average value of the activation energy for each sample based on four measurements is not more than $7 \%$.

\section{Acknowledgements}

This research was supported by the Russian Science Foundation (Grant no.19-72-10078). 


\section{REFERENCES}

1 Sharif M., Jacob J., Javed M., Manzoor A., Mahmood K., Khan M.A. Impact of Co and Mn substitution on structural and dielectric properties of lithium soft ferrites. Physics B: Condensed Matter. 2019, Vol. 567, pp. $45-50$.

2 Mazen S.A., Abu-Elsaad N.I. Structural, magnetic and electrical properties of the lithium ferrite obtained by ball milling and heat treatment. Applied Nanoscience. 2015, Vol. 5, pp. $105-114$.

3 Yurov V.M., Baltabekov A.S., Laurinas V.C., et al. Dimensional effects and surface energy of ferro-electric crystals. Eurasian phys. tech. j. 2019, Vol.16, No.1(31), pp.18-23.

4 Dun C., Xi G., Zhang Y., Zhao T., Liu Y., Heng X., Yao L. Structural, magnetic and magnetostructive properties of $\mathrm{Co}_{1-\mathrm{x}} \mathrm{Li}_{\mathrm{x}} \mathrm{Fe}_{2} \mathrm{O}_{4}$ synthesized by cathode materials of spent Li-ion batteries. Ceramic International. 2018, Vol. 44, pp. $20984-20991$.

5 Rathod V., Anupama A.V., Jali V.M., Hiremath V.A., Sahoo B. Combustion synthesis, structure and magnetic properties of Li-Zn ferrite ceramic powders. Ceramic International. 2017, Vol.43, pp. 1443114440. DOI: 10.1016/j.ceramint.2017.07.213.

6 Gan G., Zhang D., Zhang Q., Wang G., Huang X., Yang Y., et al. Influence of microstructure on magnetic and dielectric performance of $\mathrm{Bi}_{2} \mathrm{O}_{3}$-doped $\mathrm{Mg}$-Cd ferrites for high frequency antennas. Ceramic International. 2019, Vol. 45, pp. 12035 - 12040.

7 Rashad M.M., Fayed M.G., Sami T.M., El-Shereafy E.E. Structural, microstructure and magnetic properties of superparamagnetic $\mathrm{Mn}_{\mathrm{x}} \mathrm{Mg}_{1-\mathrm{x}} \mathrm{Fe}_{2} \mathrm{O}_{4}$ powders synthesized by sol-gel auto-combustion method. Journal of Materials Science: Materials in Electronics. 2015, Vol. 26, pp. 1259 - 1267.

8 Sekulic D.L., Lazarevic Z.Z., Sataric M.V., Jovalekic C.D., Romcevic N.Z. Temperature complex impedance, electrical conductivity and dielectric studies of $\mathrm{MF}_{\mathrm{e} 204}(\mathrm{M}=\mathrm{Mn}, \mathrm{Ni}, \mathrm{Zn})$ ferrites prepared by sintering of mechano-chemical synthesized nanopowders. Journal of Materials Science: Materials in Electronics. 2015, Vol. 26, pp. 1291 - 1303.

9 Şașmaz Kuru T., Șentürk E., Eyüpoğlü V. Overlaping large polaron conductivity mechanism and dielectric properties of $\mathrm{Al}_{0.2} \mathrm{Cd}_{0.8} \mathrm{Fe}_{2} \mathrm{O}_{4}$ ferrite nanocomposite. Journal of Superconductivity and Novel Magnetism. 2017, Vol. 30, pp. $647-655$.

10 Yang Y., Zhang H., Li J., Xu F., Gan G., Wen D. Effects of $\mathrm{Bi}_{2} \mathrm{O}_{3}-\mathrm{Nb}_{2} \mathrm{O}_{5}$ additives on microstructure and magnetic properties of low-temperature-fired $\mathrm{NiCuZn}$ ferrite ceramics. Ceramic International. 2018, Vol. 44, pp. 10545 - 10550. https://doi.org/10.1016/j.ceramint.2018.03.076.

11 Durgadsimi S.U., Chougule S.S., Kharabe R.G., Mathad S.N., Rendale M.K. Solid-state synthesis and structural features of $\mathrm{Li}_{0.5} \mathrm{Ni}_{0.75-\mathrm{x} / 2} \mathrm{Fe}_{2} \mathrm{O}_{4}$ ferrites. International Journal of Self-Propagating Hightemperature Synthesis. 2019, Vol. 28, pp. $71-73$.

12 Devi H.S., M. Maisnam M. Studies on the structural and piezoelectric properties of $\mathrm{ZnO}$ added on $\mathrm{Na}_{0.47} \mathrm{~K}_{0.47} \mathrm{Li}_{0.006} \mathrm{NbO}_{3}$ ceramics prepared by ceramic method using high energy ball mill. Journal of Materials Science: Materials in Electronics. 2019, Vol. 30, pp. 11458 - 11463.

13 Anjum S., Seher A., Mustafa Z. Effect of $\mathrm{La}^{3+}$ ions substituted M-type barium hexa-ferrite on magnetic, optical and dielectric properties. Applied Physics A. 2019, Vol. 125 p. 664

14 Ridgley D.H., Lessoff H., Childress J.V. Effects of Lithium and Oxygen Losses on Magnetic and Crystallographic Properties of Spinel Lithium Ferrite. Journal of the American Ceramic Society. 1971, Vol.53, pp. $304-311$.

15 Beregi E., Sterk E., Pal E., Farkas-Jahnke M. Crystal defects in flux grown lithium ferrite, $\mathrm{LiFe}_{5} \mathrm{O}_{8}$ single crystal. Hungarian Academy of Sciences. 1979, Vol. 47 pp. 263 - 273. DOI: 10.1007/BF03156535.

16 Vakhitov R.M., Shapayeva T.B., Solonetski R.V., Yumaguzin A.R. Structure of magnetic formations on the defects of ferrite-garnet films. Doklady Physical Chemistry. 2016, Vol. 470 pp. 165 - 167.

17 Kalinkin A.M., Usoltsev A.V., Kalinkina E.V., Nevedomskii V.N., Zalkind O.F. Solis-phase synthesis of nanocrystalline lanthanum zirconate using mechanical activation. Russian Journal of General Chemistry. 2017, Vol.87, pp. 2258 - 2264. https://doi.org/10.1134/S1070363217100024.

18 Surzhikov A.P., Pritulov A.M., Lysenko E.N., Sokolovskiy A.N., Vlasov V.A. Vasendina E.A. Calorimetric investigation of radiation-thermal synthesized lithium pentaferrite. Journal of Thermal Analysis and Calorimetry. 2012 Vol. 101, No.1, pp. 11-13. DOI: 10.1007/s10973-010-0788-7

19 Anjum S., Nisa M., Sabah A., et al. Comprehensive analysis of structure and temperature, frequency and concentration-dependent dielectric properties of lithium-substituted cobalt ferrites $\left(\mathrm{Li}_{\mathrm{x}} \mathrm{Co}_{1-}\right.$ $\left.{ }_{x} \mathrm{Fe}_{2} \mathrm{O}_{4}\right)$. Applied Physics A. 2017, Vol. 123, pp. 1 - 8. https://doi.org/10.1007/s00339-017-1169-x. 
20 Mahmoudi M., Kavanlouei M., Maleki-Ghaleh H. Effect of composition on structural and magnetic properties of nanocrystalline ferrite $\mathrm{Li}_{0.5} \mathrm{Sm}_{\mathrm{x}} \mathrm{Fe}_{2.5-\mathrm{x}} \mathrm{O}_{4}$. Powder Metallurgy and Metal Ceramics. 2015, Vol.54, pp. 31 - 39. DOI: 10.1007/s11106-015-9676-9.

21 Berezhnaya M.V., Mittova I.Y., Perov N.S., Al'myasheva O.V., Nguyen A.T., Mittova V.O., Bessalova V.V., Viryutina E.V. Production of zinc-doped yttrium ferrite nanopowders by the sol-gel method. Russian Journal of Inorganic Chemistry. 2018, Vol. 63, pp. 742 - 746.

22 Kumar A., Yadav N., Rana D.S., Kumar P., Arora M., Pant R.P. Structural and magnetic studies of the nickel doped $\mathrm{CoFe}_{2} \mathrm{O}_{4}$ ferrite nanoparticles synthesized by the chemical co-precipitation method. Journal of Magnetism and Magnetic Materials. 2015, Vol. 394, pp. 379 - 384.

23 Merzadinova G.T., Sakipov K.E., Sharifov D.M., Mirzo A, Bekeshev A.Z. Laser photoacoustics method for determination of the coeficients ot thermal conductivity and thermal diffusivity of materials. Eurasian phys. tech.j. 2019, Vol.16, No.1(31), pp. $94-98$.

24 Rathod V., Anupama V.A., Kumar R., Jali V.M., B. Sahoo B. Correlated vibrations of the tetrahedral and octahedral complexes and splitting of the absorption bands in FTIR spectra of Li-Zn ferrites. Vibrational Spectroscopy. 2017, Vol. 92, pp. 267 - 272. DOI: 10.1016/j.vibspec.2017.08.008.

25 Boldyrev V.V., Voronin A.P., Gribkov O.S., et al. Radiation-thermal synthesis. Current achievement and outlook. Solid State Ionics.1989, Vol .36 pp. 1 - 6 . https://doi.org/10.1016/01672738(89)90051-9.

26 Auslender V.L., Bochkarev I.G., Boldyrev V.V., et al. Electron beam induced diffusion controlled reaction in solids. Solid State Ionics.1997, Vol.103, pp. 489 - 493. DOI: 10.1016/S0167-2738(97)84073-8.

27 Surzhikov A.P., Pritulov A.M., Lysenko E.N., Sokolovskii A.N., Vlasov V.A., Vasendina E.A. Influence of solid-phase ferritization method on phase composition of lithium-zinc ferrites with various concentration of zinc. Journal of Thermal Analysis and Calorimetry, 2012, Vol. 109, pp. 63-67.

28 Surzhikov A.P., Lysenko E.N., Malyshev A.V., Vlasov V.A., Suslyaev V.I., Zhuravlev V.A., Korovin E.Y., Dotsenko O.A. Study of the radio-wave absorbing properties of a lithium-zinc ferrite based composite. Russian Physics Journal. 2014. Vol.57, No.5, pp. $621-626$.

29 Surzhikov A.P., Lysenko E.N., Malyshev A.V., Pritulov A.M., Kazakovskaya O.G. Influence of mechanical activation of initial reagents on synthesis of lithium ferrite. Russian Physics Journal. 2012 , Vol.55, pp. 672 - 677. https://doi.org/10.1007/s11182-012-9865-7.

30 Surzhikov A.P., Malyshev A.V., Lysenko E.N., Vlasov V.A., Sokolovskiy A.N. Structural, electromagnetic, and dielectric properties of lithium-zinc ferrite ceramics sintered by pulsed electron beam heating. Ceramics International. 2017, Vol. 43, No. 13, pp. 9778-9782.

31 Surzhikov A.P., Frangulyan T.S., Ghyngazov S.A. A thermoanalysis of phase transformations and linear shrinkage kinetics of ceramics made from ultrafine plasmochemical $\mathrm{ZrO} 2(\mathrm{Y})-\mathrm{Al} 2 \mathrm{O} 3$ powders. Journal of Thermal Analysis and Calorimetry. 2014, Vol. 115, No. 2, pp. 1439-1445

32 Long X., Liu Y., Yao G., Du J., Zhang X., Cheng J., Hua J. Microstructure and mechanical properties of $\mathrm{NiFe}_{2} \mathrm{O}_{4}$ ceramics reinforced with $\mathrm{ZrO}_{2}$ particles with different sintering temperatures. Journal of Alloys and Compounds. 2013, Vol. 551, pp. $444-450$.

33 Bejbl, J., Bemš, J., Králík, T., et al. New approach to brown coal pricing using internal rate of return methodology. 2014, Applied Energy, Vol. 133, pp. 289 - 297.

34 Lysenko E.N., Ghyngazov S.A., Surzhikov A.P., Nikolaeva S.A., Vlasov V.A. The influence of $\mathrm{ZrO}_{2}$ additive on sintering and microstructure of lithium and lithium titanium-zinc ferrites. Ceramic International. 2019, Vol.45, pp. 2736-2741.

35 Luchnikov P.A., Vetrova V.V., Zubkov N.P., Surzhikova, O.A. Chernova, N.I. Deformable Polymer Dielectric Films in Phase Light Modulators. IOP Conference Series: Materials Science and Engineering. 2017, Vol. 189.

36 Bemš, J., Starý, O., Macaš, M., Žegklitz, J., Pošík, P. Innovative default prediction approach //Expert Systems with Applications, 2015, Vol. 42, No 17-18, pp. 6277 - 6285.

37 Lysenko, E.N., Surzhikov A.P., Vlasov V.A., Nikolaev E.V.,Malyshev A.V., Bryazgin, A.A., Korobeynikov, Mikhailenko, M.A. Synthesis of substituted lithium ferrites under the pulsed and continuous electron beam heating. Nuclear Instruments and Methods in Physics Research, Section B: Beam Interactions with Materials and Atoms.-2017.-V.392.-pp.1-7. 